\title{
CINE Y LITERATURA EN AMÉRICA LATINA LAS INTERVENCIONES DE MARIO BELLATIN
}

\section{Carlos Leonel Cherri CEDINTEL/CONICET}

RESUMEN: En este último cambio de siglo, la literatura y el cine producido en América Latina han insistido en representar, de diversas formas, la violencia social. Dicho fenómeno ha sido definido como un "boom" estetizante de la violencia y, a la vez, como una reflexión acerca de la marginalidad de ciertos sujetos como de las relaciones biopolíticas que exponen. El presente trabajo se detiene en ciertas producciones literarias y audiovisuales de Mario Bellatin como Salón de Belleza, Bola negra - el musical de Ciudad Juárez y La escuela del dolor humano de Sechuán con el fin de abordar tal problemática.

PALABRAS CLAVES: Mario Bellatin. Cine/literatura. América Latina.

\section{CINEMA AND LITERATURE IN LATIN AMERICA MARIO BELLATIN'S INTERVENTIONS}

ABSTRACT: In the last turn of the century, literature and cinema produced in Latin America have insisted on represent, in many ways, social violence. This phenomenon has been described as an aestheticized "boom" of violence and, at the same time, as a reflection on the marginality of certain subjects and the biopolitical relations that they expose. This work focuses on certain literary and audiovisual productions by Mario Bellatin such as Salón de Belleza, Bola negra - el musical de Ciudad Juárez and La escuela del dolor humano de Sechuán in order to address such matter.

KEYWORDS: Mario Bellatin. Cinema/Literature. Latin America.

Carlos Leonel Cherri es Doctorando en Literatura de la Universidad de Buenos Aires. 


\section{CINE Y LITERATURA EN AMÉRICA LATINA LAS INTERVENCIONES DE MARIO BELLATIN}

\section{Carlos Leonel Cherri}

En la década de 1930, especialmente en La obra de arte en la época de su reproductibilidad técnica (1936), Walter Benjamin presentaba el problema de la experiencia moderna como un choque de fuerzas del que participaban la anestesia y la sensibilidad. Enfrentamiento que era bien apreciable no sólo en la guerra o en la experiencia de la ciudad moderna sino, ejemplarmente, en las artes en general y en el cine en particular: allí, un instante de peligro.

El futurista Filippo Marinetti espera en "la guerra la satisfacción artística de la percepción sensorial modificada por la técnica". ${ }^{1}$ Ese gesto, insistía Benjamin, dramatiza la anestesia fascista: ir a la guerra contemplando su belleza. La anestesia es sintomática del shock de la modernidad que hace la cotidianeidad perceptiva asimilable. Por ese camino, la humanidad se transforma en objeto de contemplación de sí misma y entra en un proceso de auto-alienación de semejante valía "que le permite vivenciar su propia aniquilación como un goce estético de primer orden". Esto es, de un modo manifiesto, sentencia Benjamin, la realización absoluta del l'art pour l'art. ${ }^{2}$ En ese contexto, el deber del comunismo era poner en relación la experiencia política con la experiencia estética. Desatender la problemática, implicaba abandonar el arte a la muerte: fiat ars pereat mundus. ${ }^{3}$

\footnotetext{
${ }^{1}$ BENJAMIN, Walter. La obra de arte en la época de su reproductibilidad técnica. In: Estética y política. Buenos Aires: Las cuarenta, 2009, p. 133.

2 Ibídem, p. 136.

${ }^{3}$ En 1949 Theodor Adorno escribe "Kulturkritik und Gesellschaft" que dos años después se publicará en Soziologische Forschung in Unserer Zeit (p. 228-240). Allí realiza, tal vez, su más polémica sentencia, declarar la imposibilidad de poesía y cultura después de Auschwitz al asumir el diagnóstico benjaminiano en la negatividad pura: cultura igual barbarie. Recientemente, Jean-Luc Nancy ha vuelto al tópico de la "prohibición de representación" argumentando que tal proposición tiene como supuesto una representación garantizada por la "voluntad de presencia", así el campo de concentración es, en realidad, "sobre-representación" y "espectáculo del aniquilamiento". (NANCY, Jean-Luc. La representación prohíbida. Seguido de La Shoah, un soplo. Buenos Aires: Amorrortu, 2006, p. 21). Desde otra óptica, Nicolas Bourriaud se ha acercado a la cuestión de la estetización de la violencia sosteniendo que la "repetición del mensaje" es "the main function of the instruments of communication of capitalism", cuyo fin es perdurar la estabilidad de los "frameworks" mediante la "decoration".
} 
En los años sesenta, vía el Tercer Cine (Cinema Novo, Cine de Liberación, etc.), el concepto resonó en América Latina. Glauber Rocha, por ejemplo, separó inmediatamente la estética de la violencia de una lectura estetizante (complaciente, contemplativa). Pues

esta violencia no está impregnada de odio sino de amor, incluso se trata de un amor brutal como la violencia misma, porque no es un amor de complacencia o de contemplación, sino amor de acción, de transformación [...] Nuestro cine es un cine que se pone en acción en un ambiente político de hambre, y que padece por lo tanto de las debilidades propias de su existencia particular. ${ }^{4}$

Al momento de pensar este cambio de siglo, en América Latina, se produce una suerte de retombée. Solo que ya no se trata de un gobierno fascista o una dictadura sino de sistemas económicos y de formas de administrar lo viviente. El escenario, también diferente, no se definiría como una guerra mundial/imperial sino como la guerra-civil en curso. $Y$ tampoco habría guerreros o héroes sino, más bien, bandidos: el bando abandonado ${ }^{5}$ de un nuevo campo biopolítico signado por el narcotráfico, las enfermedades, la racialización, la explotación y el feminicidio. Así, los espacios de estos bandos sustituirían a las fábricas, pues allí surgirían las figuras paradigmáticas de la anestesia. Susceptibles de ser transformadas en vidas sacrificables (esclavitud anónima), son la barbarie fantasmática de los documentos de la cultura y de las artes, constituyen "la regla" que es "el 'estado de excepción en el que vivimos'”. ${ }^{6}$ Y las artes, claro, vuelven a presentarse como un campo atravesado por tales fuerzas.

Otra vez en América Latina pero ya más cerca del cambio de siglo, Héctor

En tales términos el único gesto político del arte es con la "difusión de la precariedad": "undermine all the material and immaterial edifices that constitute our decor". (RYAN, Bartholomew. Altermodern: A conversation with Nicolas Bourriaud. Art in America. 2009).

4 ROCHA, Glauber. Una estética de la violencia. Nuestro Cine: revista cinematográfica. Madrid, n. 60,1967, p. 32-33.

${ }^{5}$ Explica Giorgio Agamben: “La relación de excepción es una relación de bando. El que ha sido puesto en bando no queda sencillamente fuera de la ley ni es indiferente a ésta, sino que es abandonado por ella, es decir, queda expuesto y en peligro en el umbral en que vida y derecho, exterior e interior se confunden. De él no puede decirse literalmente si está dentro o fuera del orden jurídico (es decir, a voluntad propia, a la merced de, libre, excluido como en el caso de la acepción 'bandido') [...] La relación originaria de la ley con la vida no es la aplicación, sino el Abandono. La potencia insuperable del nómos, su originaria 'fuerza de ley', es que mantiene a la vida en su bando abandonándola". AGAMBEN, Giorgio. Homo Sacer: el poder soberano y la nuda vida. Valencia: Pretextos, 2003, p. 43-44.

6 BENJAMIN, Walter. Tesis de Filosofía de la Historia. In: Discursos interrumpidos I. Buenos Aires: Taurus, 1989, p. 182 [Tesis 8]. 
Abad Faciolince (escritor y periodista colombiano) acuñó en 1994 el término sicaresca para referirse a un "boom" de novelas parecidas a "la picaresca en el sentido de que es un sujeto que narra en primera persona sus fechorías." ${ }^{7}$ Sin embargo, ese "boom" no tendría únicamente que ver con la temática del narco (la constitución de un género) sino con un gesto de fascinación por la violencia (la asunción de una posición, lógica o forma). Por consiguiente, al igual que La virgen de los sicarios (1994) de Fernando Vallejo, su texto Angosta (2003) se alejaría críticamente de dicha tendencia. ${ }^{8}$ En ese sentido, si bien el "boom" (mercadotécnico) estaría relacionado más directamente con este fenómeno de fascinación, otras producciones abordarían críticamente la cuestión. $^{9}$

La fascinación produce, según Faciolince, un "regodeo macabro" y ello supone un "peligro". En términos de Horst Nitschack dicho peligro tiene que ver con la representación de la violencia relacionada con un goce literario de la misma, tanto del autor como del lector. Para Nitschack, "La parte de los crímenes" de 2666 de Roberto Bolaño (2004) es ejemplar al respecto, pues "la repetición es permitir que el yo vuelva a funcionar, porque en la enésima repetición se produce una distancia." ${ }^{10}$ En esa "parte" un lenguaje forense describe múltiples asesinatos de mujeres en conjunto con los abusos policiales, la violencia carcelaria, la frialdad de los manicomios y la explotación de las maquiladoras.

Dicho procedimiento, insiste Nitschack, vendría a interrogarnos sobre "cómo representar la violencia sin estetizarla". Por ende, la salida de Bolaño propone el establecimiento de un foco no en la representación sino en el acto

\footnotetext{
${ }^{7}$ FACIOLINCE, Héctor Abad. Lo último de la sicaresca antioqueña. El tiempo. 1994.

${ }^{8}$ Es interesante cómo Faciolince avisoró una problemática que se encontraba germinando en la literatura, pero que pocos años más tarde el cine explotó (Rosario tijeras, Tropa de Elite, Días de Gracia...) y que se ha extendido hasta nuestros días en la televisión ( $E l$ patrón del mal, El señor de los cielos, La viuda negra...).

${ }^{9}$ Para consultar tales producciones artísticas como las propuestas críticas que las articulan ver OSPINA, Claudia. Representación de la violencia en la novela del narcotráfico y el cine colombiano contemporáneo. University of Kentucky Doctoral Dissertations, 2010; LEÓN, Christian. El cine de la marginalidad: realismo sucio y violencia urbana. Ecuador: Editorial Abya Yala, 2005; LUDMER, Josefina. Territorios. In: Aquí América Latina: una especulación. Buenos Aires: Eterna Cadencia; NOEMI-VOIONMAA, Daniel. Leer la pobreza en América Latina: literatura y velocidad. Lima: Cuarto Propio, 2004; ADRIAENSEN, Brigitte; PLA, Valeria Grinberg (Org.). Narrativas del crimen en América Latina. Transformaciones y transculturaciones del policial. Berlin: Lit. Verlag Münster, 2012; LINK, Daniel. Violencia. In: Suturas: imágenes, escritura, vida. Buenos Aires: Eterna Cadencia, 2015.

${ }^{10}$ BERMÚDEZ, Manuel. Horst Nitschack: Existe un peligroso goce literario de la violencia. Semanario Universitario. 2001.
} 
performativo; de ese modo la escenificación no reproduce lo que tematiza.

En este caso la distancia no se debe a un "alejamiento" del autor (una "presunta" objetividad como fundamento del buen registro) sino a un choque intempestivo debido a un acercamiento táctil. Justamente esta cuestión de la distancia y del contacto en torno a la representación de la violencia, es un tópico recurrente en las creaciones de Mario Bellatin. Propongo, por lo tanto, un recorrido por sus intervenciones literarias, cinematográficas y performáticas en lo que respecta al tratamiento de la violencia.

\title{
ACERCA DEL REGISTRO: VIOLENCIA E IMAGINACIÓN
}

En un fragmento de La escuela del dolor humano de Sechuán de Mario Bellatin, titulado "Noticias del pedagogo", hay una imagen en la que cuerpo, fotografía y máquina entablan un contacto:

\begin{abstract}
Entre otras manifestaciones, aun más inverosímiles, los ciudadanos, campesinos principalmente, empiezan a fotografiarse empuñando armas rudimentarias. Casi todas las representaciones muestran a los personajes haciendo coincidir el momento exacto del disparo de la fotografía con la acción violenta que el arma empuñada es capaz de llevar a cabo. En algunas provincias se han suscitado una serie de situaciones trágicas al haber sido despedazado el fotógrafo en el preciso instante de obturar su disparador. Es común asimismo apreciar álbumes familiares con las fotos totalmente mutiladas por acción de un arma punzo cortante. ${ }^{11}$
\end{abstract}

Captar el movimiento original de la acción violenta implica una coincidencia temporal con la acción de su registro ("el disparo de la fotografía") cuya consecuencia "trágica" no es solo el despedazamiento del fotógrafo sino, también, la mutilación de la imagen (familiar). En otras palabras, captar ese momento demanda un principio de presencia ("estar justo ahí") que expone no tanto una pasión por el testimonio o el documento sino por el registro de una violencia que no haría más que expandir su potencia.

Pero si nos detenemos en la imagen, se puede percibir cómo la "noticia" del pedagogo funciona, más bien, como una suerte de aviso (notificación) de nuestra relación vital y erótica con las imágenes. Que, como señala Jean-Luc Nancy, no es otra cosa que su disponibilidad a ser tomadas. Es decir:

\footnotetext{
${ }^{11}$ BELLATIN, Mario. La escuela del dolor humano de Sechuán. In: Obra reunida. México: Anagrama, 2005, p. 442.
} 
tocadas con los dedos, con las manos, con el vientre o con la razón, y penetradas [...] Pero penetrar la imagen, así como una carne amante, quiere decir ser penetrado por ella. La mirada se impregna de color, el oído de sonoridad. Nada hay en la mente que no esté en los sentidos: nada en la idea que no esté en la imagen. Me convierto en el azul del retrato de Olga, la disonancia de un acorde, la cabriola de un paso de baile. "Yo»: ya no es cuestión de «yo». Cogito deviene imago. $^{12}$

El devenir-imago implica, entonces, que el sujeto entra en una inmixión con la imagen y deja de percibirse exterior e individual para recaer en la continuidad sin afuera de lo sensible. ${ }^{13}$ Nancy llama a esto con-venir: entrar en la imagen, ya no mirarla - si bien se sigue ante ella - "el espectador la penetra, es penetrado por ella: de ella, de su distancia y de su distinción, al mismo tiempo". ${ }^{14}$ Al parecer, Nancy sigue a Georges Bataille, puesto que el erotismo de la imagen se sostiene en la medida que "toda la operación erótica tiene como principio una destrucción de la estructura del ser cerrado que es, en su estado normal, cada uno de los participantes del juego". ${ }^{15}$

Pero el erotismo demanda una distinción y una distancia como "puros medios", que no se encuentra, por ejemplo, en la lógica del dispositivo pornográfico que captura y neutraliza la "capacidad humana de hacer girar en el vacío los comportamientos eróticos, de profanarlos" puesto que el "consumo solitario y desesperado de la imagen pornográfica sustituye, así, a la promesa de un nuevo uso". ${ }^{16}$ Si bien Nancy no usa esta palabra, al igual que la imagen mutilada de Bellatin, nos deja una notificación problemática: "distinguir entre la atracción del deseo y la seducción de lo espectacular no es, con todo, tan fácil como algunos quisieran..."17

\footnotetext{
${ }^{12}$ NANCY, Jean-Luc. La imagen-Lo distinto. Laguna: Revista de filosofía, n. 11, 2002, p. 18.

${ }^{13}$ Para Buck-Morss "el circuito que va de la percepción sensorial a la respuesta motora comienza y termina en el mundo. Así, el cerebro no es un cuerpo anatómico aislable, sino parte de un sistema que pasa a través de la persona y su ambiente (culturalmente específico, históricamente transitorio). [...] El campo del circuito sensorial, entonces, se corresponde con el de la 'experiencia', en el sentido filosófico clásico de una mediación de sujeto y objeto, y sin embargo su misma composición vuelve simplemente irrelevante la así llamada 'división entre sujeto y objeto', que era la plaga persistente de la filosofía clásica". BUCKMORSS, Susan. Walter Benjamin. Un escritor revolucionario. Buenos Aires: Eterna Cadencia, 2005, p. 182.

${ }^{14}$ NANCY, Jean-Luc. La imagen-lo distinto, op. cit., p. 17.

15 Ídem, El erotismo. Barcelona: Tusquest, 1988, p. 17.

${ }^{16}$ AGAMBEN, Giorgio. Elogio a la profanación. In: Profanaciones. Buenos Aires: Adriana Hidalgo, 2005, p. 118.

${ }^{17}$ NANCY, Jean-Luc. La imagen-lo distinto, op. cit., p. 14.
} 
Otros fragmentos de La escuela del dolor parecen insistir con este pensamiento. Por un lado, tenemos el relato de un grupo de voleibol llamados Los democráticos cuyos integrantes carecen de dedo pulgar. Y por otro lado, tenemos el relato de un conjunto de personas cuyos pulgares fueron amputados a modo de castigo, puesto que faltaba la tinta del sufragio en sus dedos, es decir, no había marca para constatar un voto, una presencia. Como el texto deja ver, el momento del acto violento se encuentra sugerido eróticamente, pero esa última imagen o palabra, que funcionaría como la imagen originaria de la violencia se encuentra en falta. Los indicios están al alcance de la mano (ya sin dedos). $Y$, aunque la posibilidad asociativa se ubique en una proximidad máxima, asintótica podríamos decir, hay una distancia (interpretativa) que solo puede atravesarse imaginariamente.

En otras palabras, hacer esa experiencia imaginaria, podría llevarnos a pensar que Los democráticos han configurado una tecnoestética: en el deporte (vóleibol), ahí donde superviven los restos de un patriotismo bélico, han politizado una falta: una ausencia de algo o alguien, una nota o registro, un quebrantamiento de una obligación, una transgresión de las reglas de juego. Como burlándose, ellos posan: se han aprovechado del espectáculo para extraer su potencia especular. Es decir, han encontrado las formas y las circunstancias para mostrar algo: "entre otras cosas, cómo una mano sin dedos es capaz de duplicar la potencia del golpe en una pelota". ${ }^{18}$

Estamos frente a una lógica recurrente en el sistema creativo de Bellatin y que, a lo largo de su obra, ha funcionado de diversas formas. En Salón de Belleza (1994), por ejemplo, la enfermedad incurable carece de nombre. Haber vaciado el nombre es lo que instaura un clima de indeterminación y despliega las fuerzas de la imaginación. Los lectores, pensando en el sida, han querido librar la ficción en este último fin de siglo u, optando por las pestes antiguas, han perseguido el moridero hasta la Edad Media.

Pero esto no es un daño colateral, sino que Salón de Belleza ha dispuesto a la sazón esos posibles referenciales o alegóricos como mecanismo de atracción. Esa "falsa retórica" permite que, al igual que Los democráticos, Bellatin se aproveche de la seducción de lo espectacular - la literatura testimonial, lo autobiográfico, el imaginario del sida y de lo medieval - para sacar de ese orden de cosas una diferencia que "duplique la potencia del golpe". Salón de

${ }^{18}$ BELLATIN, Mario. La escuela del dolor humano de Sechuán, op. cit., p. 444. 
belleza sería uno de los experimentos estéticos de una pregunta que Bellatin ha formulado directamente: "cómo hacer literariamente un texto que sin ser horroroso, me permitiera hablar de horrores." 19

Es curioso que esta pregunta entra en resonancia con los modos en que Bellatin ha regresado a la versión teatral de Salón de Belleza adaptada por Alberto Chimal e Israel Cortés y presentada en el 2002 por la Compañía Mexicana de Circo de Cámara, Circo Raus. Este pasaje se encuentra en varios textos, como Lecciones para una liebre muerta (2005), Biografía ilustrada de Mishima (2009) e, incluso, en algunas entrevistas y presentaciones públicas. La versión de la Biografía tiene la singularidad de encontrarse en tercera persona del singular $y$, justamente por eso, el protagonista del relato no es un sujeto sin nombre sino "Mishima", que habría comprobado el terror del carácter profético de la palabra escrita cuando se vio envuelto, quince o veinte años después de haberlas concebido, en situaciones similares a las que aparecían en sus textos

Recordaba con mucha claridad, por ejemplo, cuando se realizó el montaje teatral de su libro Salón de belleza. Desde un comienzo había decidido no intervenir de manera directa en aquella puesta en escena. Confió el texto a un director a quien admiraba [...] No había asistido a ninguno de los ensayos. Todo era sorpresa. En aquel teatro fue la primera vez que pudo leerse a sí mismo. El texto original había sido respetado por completo, pero su estructura estaba absolutamente modificada [...] ¿Qué clase de espanto ha sido capaz de generar una escritura semejante?, recuerdo que fue la pregunta que surgió en ese momento.

Sin embargo, en el aparente universo abyecto que veía representarse en escena, Mishima creyó descubrir la existencia de una realidad plena. Lo que fue sucediendo en el escenario apareció con una luminosidad de la que carecía la vida cotidiana. En ese momento advirtió que quizá una de las razones que lo habían llevado a la escritura [... fue] la necesidad de apreciar ese estado paralelo de la realidad semejante al que se mostraba en la obra de teatro, al cual debía pertenecer para poder vivir plenamente. Daba la impresión de que mientras más sórdido fuese lo representado, se cumplía de una manera más clara el cometido. Mishima se dio cuenta de que el mecanismo podía consistir en colocar un universo terrible como si fuese una suerte de escudo contra lo que ese mismo mundo iba produciendo. ${ }^{20}$

Al igual que en los fragmentos de Los democráticos, la imagen que ha pro-

${ }^{19}$ GOLDCHLUK, Graciela. Mario Bellatin, un escritor de ficción. Entrevista a Mario Bellatin. México, marzo, 2000, p. 7.

${ }^{20}$ BELLATIN, Mario. Biografía ilustrada de Mishima. Buenos Aires: Entropía, 2009, p. 50-51. 
ducido semejante espanto/horror gira en el vacío, se nos sustrae y, por eso, lo terrible no puede ni debe restituirla, sino funcionar como un escudo contra lo que eso mismo produce.

En el 2014 se cumplió el vigésimo aniversario de Salón de belleza, y Andrea Pallaoro director de Medeas (2013) ha comenzado a filmar una versión del texto. Sin embargo, Bellatin ha optado por realizar su propia versión de aniversario. Pero no se trata de un mero texto fílmico sino que recurre a la potencia del acontecimiento de la performance o del happening: el resultado es el cine-vivo.

\section{EXPERIMENTOS Y ARQUEOLOGÍAS}

El miércoles 15 de julio de 2015 se presentó en La plata, por segunda vez, Salón de belleza. Se trata de una película desarrollada junto a una lectura realizada por Bellatin de un texto cualquiera. La propuesta es, entonces, explorar la pérdida de unicidad temática y temporal entre imagen, sonido y palabra.

Expuestos a semejante multiplicidad azarosa de sentido, los materiales se revelan como la persistencia de una escritura. $Y$, por eso mismo, Mario Bellatin sería el principio de acción o de realización de dicha puesta, performance, cine, escritura, etc. Su presencia se vuelve, así, el principio de vaciado constitutivo que permitiría que el texto funcione y el lector no esté solo frente a tales imágenes (escritas, sonoras, visuales) sino que con-venga con ellas a través de formas singulares y cualquieras.

Es interesante detenerse en la película que, lejos de mostrar un tinte abstracto, cita directamente al texto homenajeado. Se tratan de cuatro partes y una suerte de "ending". La primera son secuencias de planos cerrados de peceras. La segunda, el recorrido de una suerte de casona o salón en el que una serie de cuerpos se encuentran tapados totalmente con mantas. En la parte tercera la cámara deambula por las calles de una ciudad deteniéndose, especialmente, en los tratamientos cosméticos que se realizan al aire libre. Finalmente, la última parte es una incursión en un baño público.

Como vemos, los elementos de la película restituyen directamente los del texto Salón de belleza: las peceras, el salón de belleza vuelto moridero y el paseo urbano hacia los baños públicos. Sin embargo, hay una diferencia tajante en la topología de los elementos y el montaje de los mismos. Si el texto y sus relatos van intercalando estos elementos, el film evitó homologar tal montaje. 
Si en el texto el salón de belleza se transforma en un moridero al ritmo que arrastra consigo a las peceras y al cuerpo del estilista que se estigmatiza, clausurando las salidas a los baños públicos; en el film estos elementos están dispuestos en una continuidad que no los relaciona ni intercala, solo los pone en sucesión y distinción.

En la película no vemos ninguna pecera en un salón de belleza, sino un conjunto de peceras que, además del infinito, nos sugieren la idea de pecera, no tanto como espacio cerrado, sino como un fragmento de un espacio mayor que se ha cerrado en sí mismo estableciendo una distancia no tanto espacial sino visual: la división de la luz provocada por el agua, la transparencia material del vidrio. Lo mismo pasaría en la casona, especialmente en la escena en que se sale a una terraza: es decir, a un umbral que abre la casa al mundo. Continuando esta idea, la mayoría de los tratamientos cosméticos sucede en la calle. Otra vez no es un espacio cerrado, sino un fragmento de un espacio que se cierra sobre sí por medio de acciones que lo distancian y distinguen de un fondo (tránsito urbano indiferenciado): mujeres sentadas, recostadas, estilistas exfoliando su piel, etc. Si bien el baño público es el espacio cerrado del texto ya que a diferencia del resto no hay margen de apertura a nada, el vapor potencia la cuestión del encierro no tanto como algo espacial sino como una forma de visualidad. Por eso, mientras que avanza el texto la salida a los baños es lo que se suspende; en la película, el baño público es el lugar sobre el que se cierra esa suerte de "no relato". La película concluye, sin enfermedad alguna, luego de mostrar la versión de la canción infantil "El diablito loco" realizada por Teresa Brewer en 1958, titulada "Pickle up a doodle".

Una vez concluida la proyección, se generó un espacio de intercambio del que Bellatin participó. Ante la pregunta por la realización de la película, el autor contó que fue realizada, en mayor medida, por niños. Que todas las locaciones quedaban cerca de su casa en México. Algunas, como la calle de tratamientos cosméticos, a la vuelta de su manzana. La única parte del film que registró exclusivamente Bellatin fueron las imágenes del baño público. El método fue sencillo: el creador adaptó una cámara a su prótesis esperando que "la corrección" de las personas les impidiera mirar su brazo y percatarse de que estaban siendo filmadas. La cámara estaba ubicada tras su brazo, de modo que él no era totalmente consciente de lo que se encontraba registrando. La única imagen que tomó voluntariamente es la de su hijo, Tadeo Bellatin, afeitándose. En otras palabras, ante la pregunta de ese lector 
imaginario frente a la realización teatral de Salón de belleza, la nueva respuesta que el Salón de belleza del cine-vio esboza veinte años después sería: el espanto que produjo esta escritura es un paseo por la ciudad latinoamericana de fin de siglo. ${ }^{21}$

$Y$, aunque el autor insista que el cine-vivo pone aprueba lo rudimentario como principio creativo (un presupuesto mínimo, pocos recursos técnicos) demostrando que lo único que se necesita para crear es el deseo. ${ }^{22}$ Fue más interesante comprobar la persistencia de una inquietud arqueológica o archigráfica que, aunque soslayada por la crítica, insiste en el sistema creativo de Bellatin. Como si para formar parte de la ficción ("estado paralelo de realidad") fuera necesario atravesar lo real: la exigencia de hacer la experiencia de un viaje, no a lo otro, sino a lo mismo, a lo inmediato, a lo naturalizado, a la realidad-ficción fabricada por los medios, a lo que estaría formando parte del drama biopolítico que es el presente. ¿Por qué alguien que defiende la composición de mundos autónomos filmaría a su hijo, a su barrio e incursionaría en un baño público? ¿Por qué no simplemente montar una escenografía, convocar amigos y recrear lo que sea necesario? Preguntas similares podríamos hacerle al film Bola negra - el musical de Ciudad Juárez.

En el 2012, Mario Bellatin y Marcela Rodríguez se formularon una pregunta: ¿Qué pasa en Ciudad Juárez? La pregunta no surgía de la desinformación sino que el escritor y la compositora sospechaban que los relatos instalados por los medios de comunicación, la industria cultural, la política y el rumor eran falsos. Por eso, Bellatin y Rodríguez tomaron como primera medida ir al

${ }^{21}$ Es decir, el horror producido por la destrucción de la experiencia que, como sabemos, para que suceda no es de "ningún modo necesaria una catástrofe y que la pacífica existencia cotidiana en una gran ciudad es, a ese fin, perfectamente suficiente". AGAMBEN, Giorgio. Infancia e historia. Buenos Aires: Adriana Hidalgo, 2007, p. 7.

${ }^{22}$ Principio que podríamos rastrear hasta el relato de la escritura del libro de la infancia (1970) que figura en Underwood Portátil Modelo 1915: "En pocas semanas quedó listo un ejemplar de historias de perros, ilustrado además de manera rudimentaria por mí mismo". BELLATIN, Mario. Underwood Portátil. Modelo 1915. Revista Fractal, n. 32, enero-marzo, 2004, p. 103140. En la edición de Obras completas (2005) se ha borrado la exposición del proceso que nos interesa. Como si todo lo que representa algún valor debe ser vaciado, borrado, agujereado. Una vez percatado el proceso, el lector no puede sino enfrentarse con una materialidad-invisible (valga el oxímoron para el tachado): "En pocas semanas quedó listo un ejemplar de historias de perros, ilustrado además [de manera rudimentaria] por mí mismo." Ibídem, p. 501. ¿Se trata de una ausencia? ¿O, en realidad, hay aun allí una partícula que se disocia del saber o no su (in)visibilidad, tachado o vaciado? Si hay allí algo que insiste, persiste, ex-crito no importa tanto saber qué es (tal imagen o tal cuerpo) sino que esas líneas, que no es preciso ver para imaginarlas, lo atraviesan. Para reflexionar acerca de la visibilidad de las signaturas y los diagramas ver LINK, Daniel. 1879. In: Suturas, op. cit. 
lugar y atravesarlo. Quien pretende aproximarse a lo "sepultado tiene que comportarse como un hombre que excava" dice Walter Benjamin. ${ }^{23}$ Bola negra - el musical de Ciudad Juárez ( 56 min.) es el registro de esa empresa y experiencia arqueológica. Excavemos, pues, ese resto.

La primera imagen es una afirmación: este lugar. Al principio vemos un conjunto de casas que nos sugieren la idea de un poblado, pero en la medida que sube la cámara abriendo el plano, el poblado se difumina en la extensión de lo que sería una ciudad que, a la vez, se pierde en el desierto. No se trata de tres cosas diferentes (el pueblo, la ciudad y el desierto). Por eso, la imagen insiste en su continuidad y repite la transición: vemos dos hombres haciendo un fuego al pie de una montaña, unas casas rudimentarias y, otra vez, la extensión urbana. Ahora la cámara se pone en movimiento. Rodea la montaña, nos muestra una suerte de muralla natural de tierra y arena cuyos límites superan el encuadre: ¿Una frontera? La imagen se detiene en un vehículo policial que a la vez este se detiene cuando intercepta otro vehículo. Se escucha un coro que repite: "En realidad, se trataba del bicho deglutido por sí mismo." El plano se corta, y lo que la cámara comienza a recorrer son predios industriales. Ya no hay calles de tierra, sino asfalto; no hay vehículos policiales sino autobuses y autos. Por fin vemos la imagen del coro: solo sus manos sosteniendo unos cuadernillos. El coro pasa de tararear acordes a repetir una suerte de aspiración brusca. Junto con esa opresión sonoro-respiratoria, empieza y termina el film a la vez que aparecen y desaparecen los rostros de los cantantes del coro: unos jóvenes. En ese momento, la voz de Bellatin comienza a leer un texto.

La película repite esa estructura bífida. Por un lado, un recorrido por Ciudad Juárez y, por otro, la filmación de los ensayos del coro. El montaje va intercalando las respectivas imágenes y sonidos generando solapamientos y simultaneidades que disparan los sentidos. La cámara se mueve rápidamente, mostrando edificaciones vacías y destruidas que parecen el resto de una catástrofe. De fondo el coro, con fuerza y con estridencia, insiste: "hasta hartarse", "consumido por sí mismo", "descarnado pero vivo", "el profeta". Las transiciones son cortes que muestran las antípodas de lo mismo: el asfalto, los predios industriales y sus estacionamientos repletos de autos - el coro insiste. Otra transición: Un local comercial con letreros: "se vende", "se renta", "se vende barato". Vemos, incluso, un local de estética y un club deportivo.

\footnotetext{
${ }^{23}$ BENJAMIN, Walter. Desenterrar y recordar. In: Cuadros de un pensamiento. Trad. Susana Mayer. Buenos Aires: Imago Mundi, 1992, p. 118.
} 
Pero no hay nadie, no pasa nada. Rara vez, una persona: un joven caminando en una calle desierta con dirección a la montaña ( $\min 6-11)$.

En el salón el coro se encuentra ensayando, Rodríguez los dirige y Bellatin retoma la lectura:

la receta consistía en destazar el pez hasta dejarlo descarnado pero vivo, para luego introducirlo en una pecera que sería puesta en el centro de la mesa de los novios. La pareja de recién casados comería la carne mientras el animal seguía nadando, moribundo, mostrando sus órganos internos a todo el que quisiera verlos. Como señal de buen augurio para el matrimonio, la comida debía durar el tiempo exacto que tardaba el pez en morir.

Mientras la lectura se desarrolla el coro sigue repitiendo sus frases y la cámara se mueve encuadrando los pies de los jóvenes y las botellas de agua que hay en el suelo. Vemos a Rodríguez que dirige, hasta el silencio, una suerte de canto animal similar por su simultaneidad y variación al de ciertas aves o incluso al croar de las ranas. La cámara enfoca a Bellatin que, enfocado por el silencio, continúa con la lectura:

Mientras la vieja sirvienta suplicaba y se negaba a separar nuevamente las mandíbulas, Endo Hiroshi entendió que aquella bola era el estómago del insecto. El estómago de los insectos si es que los insectos contaran con estómago. En realidad, se trataba del bicho deglutido por sí mismo

Bola negra se publicó por primera vez en 2005 en dos ediciones simultáneas: Tres novelas (Ediciones El Otro El Mismo) y Obra reunida (Anagrama). El texto breve relata un viaje en el que Endo Hiroshi, entomólogo japonés, descubre un insecto. En el viaje de regreso transporta el insecto en una caja. Al abrirla, lo que encuentra no es el insecto sino una diminuta bola negra que, supone Hiroshi, se trataría del "bicho deglutido por sí mismo".

En síntesis, Bellatin no realiza un texto exclusivo para la película y sus circunstancias sino que escoge uno ya escrito. Esa operación presenta a la creación como un montaje que pone a funcionar ciertos elementos y no otros. Así, el texto se vuelve un archivo o pretexto de la película. Al mismo tiempo, la película se transforma en una relectura del texto (un post-facio), a la vez que el origen foráneo y cualquiera del texto, vía el azar y la experimentación, instaura un efecto de distanciamiento. El film, de hecho, no oculta sino que expone el procedimiento desde el título: "Bola negra". 
Según Rodríguez, acercarse e intervenir en lo social es uno de los problemas de la composición contemporánea. Bellatin, de acuerdo con esta idea, escoge ese texto ( $y$ no otro) cuyo carácter extremo tuvo como objetivo incrementar exponencialmente el reto. ${ }^{24}$

Entonces, si entendemos por distancia "la puesta en manifiesto de la ajenidad respecto de lo que se filma" ${ }^{25}$, no podríamos adscribir semejante operación al film sino manifestando su complejidad o problematicidad. Puesto que el texto pre-concebido instala posibilidades de sentido cualesquiera no para distanciarse de lo real sino para exponer la dificultad que semejante contacto implica. Es decir, si hay distancia es del orden de lo imaginario.

Por eso, hay una particularidad y una proximidad que también se establece desde el título: Ciudad Juárez. Lo que vemos, en efecto, es eso. No se trata de ningún montaje. Incluso los adolescentes no son ni actores ni cantantes profesionales sino asistentes a clases de canto ofrecidas en Ciudad Juárez por el INBA (Instituto Nacional de Bellas Artes): es decir, son ciudadanos. El film, en ese sentido, es documental. Pero al no tratarse del buen registro de un material probatorio tal designación también es compleja ya que no se clausura la ficción por aspirar a verdad alguna. Se trata, más bien, de mostrar algo que ni siquiera se sabe qué es. Sin embargo, en tanto archi-grafía lo que sí sabe el texto es exponer una "imagen de quien recuerda" e "indicar no sólo de qué capa provienen los hallazgos sino, ante todo, qué capas hubo que atravesar para encontrarlos." 26

Ese pensamiento cobra mayor tesitura en cierta escena. Rodríguez fuma sentada en el marco de una ventana y Bellatin merodea las casas vacías encontrando diferentes objetos que va colocando en dicho marco, al lado de Rodríguez: dos zapatos, un tenedor, una lata, etc.

El film, entonces, no es tanto la respuesta a ¿Qué pasa en Ciudad Juárez? sino la formulación estética de semejante pregunta. Las imágenes son puras:

\footnotetext{
${ }^{24}$ MACMASTERS, Merry. Bola negra, el musical de Ciudad Juárez "un homenaje a jóvenes víctimas de grupos de poder". La jornada. 2013.

${ }^{25}$ Para un ejemplo de conceptualización del concepto "distancia" desde una óptica autonomista ver a OUBIÑA, Daniel; FELIPELLI, Rafael. Las pobres maneras de ejercer un oficio. Punto de vista, n. 88, Buenos Aires, agosto 2007, p. 36. Los autores celebran Copacabana de Martín Rejtman por recurrir mediante el uso de los lentes como el tamaño de los planos al "sistema más pertinente que el cine y todas las artes tienen para hacerlo: distanciándose". Lo que constituye "una mirada austera, discreta y precisa: la de un cineasta responsable".

${ }^{26}$ BENJAMIN, Walter. Excavar y desenterrar. In: Cuadros de un pensamiento, op. cit., p. 118.
} 
al no tener relato son, como quería Kafka, musicalmente silenciosas. ${ }^{27}$ Las voces son puras: no la articulación de un lenguaje, sino la potencia del canto como forma de señalar los cuerpos. ${ }^{28}$

Al vibrar la materialidad de las imágenes sonoras y visuales transforman el texto en una interrogación de sí: ¿qué son esas imágenes? ¿Qué pasa en Bola negra - el musical de Ciudad Juárez? El horror, dicen los creadores. En efecto. Pero un horror completamente distinto al que cuentan los relatos instalados. Puesto que en Ciudad Juárez, en realidad, no pasa nada. Es decir, si algo pasa no tiene que ver con un descontrol y un caos que el Estado no puede manejar, sino todo lo contrario, sucede tranquila y cotidianamente sin catástrofe alguna: es el horror biopolítico de la administración de lo viviente. ${ }^{29}$ Por eso mismo, como el título lo dice, un musical. El gesto es una incorrección política y una provocación pero, sobre todo, una potencia de vida que, como Los democráticos, sustrae del espectáculo lo que tiene de especular y de vital no para decir cosa alguna sino para mostrar algo: en el medio de una sociedad que se ha devorado a sí misma hay, todavía, canto. Descarnado pero vivo, dice el coro. En fin: la potencia del golpe.

La última imagen de ese trilema singular (Bola negra, el musical, Ciudad Juárez) es el rostro de una muchacha. Ella se encuentra sonorizando una respiración brusca, parece un chillido. $Y$, de repente, el sonido se pierde. Su rostro, angustiado, continúa respirando. Al verla, ante ella (la muchacha/la imagen/el texto/lo real) se sabe que, como en Josefina la cantante, lo que chiIla no es el chillido. Pues, como recuerda Daniel Link, el sonido se propaga en-

\footnotetext{
${ }^{27}$ Recuerda Roland Barthes: "«La condición previa de la imagen es la vista», decía Janouch a Kafka. Y Kafka, sonriendo, respondía: «Fotografiamos cosas para ahuyentarlas del espíritu. Mis historias son una forma de cerrar los ojos». La fotografía debe ser silenciosa (hay fotos estruendosas, no me gustan): no se trata de una cuestión de «discreción», sino de música. La subjetividad absoluta sólo se consigue mediante un estado, un esfuerzo de silencio (cerrar los ojos es hacer hablar la imagen en el silencio). La foto me conmueve si la retiro de su charloteo ordinario: «Técnica», «Realidad», «Reportaje», «Arte», etc.: no decir nada, cerrar los ojos, dejar subir sólo el detalle hasta la conciencia afectiva". BARTHES, Roland. La cámara lúcida. Buenos Aires: Paidós, 1990, p. 104.

${ }^{28}$ Dice Leonardo: "allí donde hay voz, hay cuerpo". Cf. AGAMBEN, Giorgio. Infancia e historia, op. cit., p. 7.

${ }^{29}$ Se trata de una transformación de los dispositivos que exhibe un estado de la técnica, es decir del saber/poder, que permite que algunos vivan más allá de sus posibilidades naturales, generando una economía de la vida que se consigue a costa de la exposición a la muerte de otros (matando sin cometer delito). Por eso en la sociedad actual entre la vida de uno y la muerte de otro se encuentra la relación que Michel Foucault llamó biopolítica. Ver FOUCAULT, Michel. Derecho de muerte y poder sobre la vida. In: Historia de la sexualidad I: La voluntad de saber. Buenos Aires: Siglo XXI, 2005.
} 
torno a un vacío y lo importante no es encontrar origen alguno sino captar el movimiento que siempre deja un residuo y seguirlo, aunque el origen del sonido se pierda.

No es nada azaroso, entonces, este final donde el sonido se va perdiendo y lo que resta es el rostro. Si lo pensamos, al igual que el título y la película misma, el rostro también es un trilema: una compleja síntesis donde convergen "la sensación física, la reacción motora, y el significado psíquico". ${ }^{30}$ Y la unidad de esa convergencia que es un lenguaje mimético y no conceptual, es el gesto. En semejante encrucijada trilemática "a lo real no accederemos nunca sino a través de los fantasmas de la imaginación, entendida ahora como enunciación colectiva, deixis pura, misticismo". Esa, la insistencia de Bola negra: lo indecible, lo necesario de la historia se juega en esos señalamientos. ${ }^{31}$

\section{ALIANZAS CONTRA NATURA Y FORMAS-DE-VIDA}

Así las cosas, la distancia y el contacto en Bellatin son formas de darse una misma operación que busca entablar nuevas relaciones con el mundo. Lo mismo podríamos decir de lo particular y lo cualquiera, de la escritura y de la imagen, del relato y de la materialidad del lenguaje. Se trata de exponer las lógicas y puntos de fuga que atraviesan el registro de cada dispositivo artístico. Donde "dispositivo artístico" no aludiría, en absoluto, a las políticas que resguardan un "tipo", un "género", unas "unidades" o unos "materiales" sino, más bien, al abandono de toda ontologización para buscar, no tanto una especificidad o una especie, sino una alianza contra-natura. ${ }^{32}$ De ahí la "advertencia-noticia" de La escuela del dolor humano, y por eso mismo, el cine se alianza con la performance, como la escritura y la música con la imagen visual.

En los textos de Bellatin siempre hay una alianza u operación bipolar. $Y$ aparece como vimos, ejemplarmente, en lo que respecta al tratamiento de la violencia. Se trata, dice el autor, de utilizar al horror como escudo contra el horror. O, por otro lado, de instaurar una "falsa retórica". Sin embargo, podríamos ensayar otra lectura que, a su vez, no descarta sino que incorpora lo anterior.

\footnotetext{
${ }^{30}$ BUCK-MORSS, Susan. Walter Benjamin. Un escritor revolucionario, op. cit., p. 184-185.

${ }^{31}$ Para la relación sonido-memoria y vacío-verdad consultar LINK, Daniel. Fantasmas: imaginación y sociedad. Buenos Aires: Eterna Cadencia, 2009, p. 118.

${ }^{32}$ DELEUZE, Gilles; GUATTARI, Félix. Mil mesetas. Madrid: Pre-texto, 2004, p. 247.
} 
Lo que las operaciones de Bellatin provocan es la generación de un espacio vacío (índex, deixis) allí donde también podría haber una presencia (relato, discurso, historia, verdad). No una disyunción (esto o lo otro) sino una simultaneidad y una multiplicidad. Por consiguiente, ya no hay antinomia entre narrar o describir, mostrar o participar, distanciarse o contactar, estetizar la violencia o politizar la estética, erotismo o pornografía, autonomía o heteronomía. En la medida que los dos elementos así como se diferencian ( $A$ y no-A) se vuelven indiferentes (ni $\mathrm{A}$ ni no-A) dándose una tensión que constituye un tercer elemento que no puede ser, sin embargo, un nuevo elemento homogéneo y similar a los anteriores sino "la neutralización y la transformación de los dos primeros". ${ }^{33}$ En la medida que "todo fenómeno es el origen y toda imagen es arcaica" ${ }^{34}$, el autor como el lector se vuelven (cada uno a su manera) los arqueólogos de ese espacio agujereado, empresa que Bellatin llama escritura pero que también tiene por nombre imaginación. ${ }^{35}$ Atravesar ese espacio, hacer la experiencia en vez de salvaguardarse en un relato, en su ausencia o en su prohibición, implica recuperar la posibilidad de ver, de oír, de sentir: no ya una pedagogía de la mirada, la escucha, o el refinamiento de los sentidos para capturar tal cosa, sino una experiencia radical del contacto con el mundo, es decir, con la vida de las imágenes. ${ }^{36}$

Dicho gesto no es coetáneo a huir de la realidad o a separar las formas de la vida: "el gran error, el único error, sería creer que una línea de fuga consiste en huir de la vida, evadirse en lo imaginario o en el arte. Al contrario, huir es

${ }^{33}$ AGAMBEN, Giorgio. Estado de excepción. Homo Sacer, II, I. Buenos Aires: Adriana Hidalgo, 2007, p. 12-13.

34 Ídem, Signatura rerum: sobre el método. Buenos Aires: Adriana Hidalgo, 2009, p. 41.

${ }^{35}$ DIDI-HUBERMAN, Georges. El archivo arde. Trad. Juan Ennis. In: Didi-Huberman, Georges; KNUT, Ebeling. Das archiv brennt. Berlin: Kulturverl, 2007.

${ }^{36}$ Esta operación, según Buck-Morss, implica "deshacer la alienación del sensorium corporal, restaurar la fuera instintiva de los sentidos corporales humanos por el bien de la autopreservación de la humanidad". BUCK-MORSS, Susan. Walter Benjamin. Un escritor revolucionario, op. cit., p. 169-171. Sería interesante poner en relación esta idea de la auto-preservación para un texto que trata, justamente, de la auto-fagia. A partir de otro recorrido, Emanuele Coccia llega a una idea similar respecto de la relación vital del hombre con las imágenes (con el mundo): "O sensível (a existência fenomênica do mundo) é a vida sobrenatural das coisas - a vida das coisas além da sua natureza, para além da sua existência física - e, simultaneamente, a sua existência infra-cultural e infra-psíquica. O meio é um fragmento de mundo que permite às formas prolongarem sua vida para além de sua natureza e de sua existência material e corpórea". Es decir, "graças às imagens, a matéria nunca está inerte, mas sim maleável e cheia de forma, e o espírito nunca é pura interioridade, mas sim técnica e vida mundana. As imagens têm uma função cosmológica e não meramente gnoseológica ou física". COCCIA, Emanuele. A vida sensível. Trad. Diego Cervelin. Florianópolis: Cultura e Barbárie, 2010, p. 37, 40. 
producir lo real, crear vida, encontrar un arma. ${ }^{\prime 37}$ Bellatin lo sabe, y por eso mismo, lo que vemos en sus producciones no solo es una radical interrogación de lo viviente sino también el viaje de huida siempre hacia adelante que produce lo real, crea vida, encuentra armas. Esa, su bioestética.

${ }^{37}$ DELEUZE, Guiles; PARNET, Claire. Diálogos. Valencia: Pretextos, 1980, p. 58. 